\title{
EFFECT OF FIRE ON BIRD AND SMALL MAMMAL COMMUNITIES IN THE GRASSLANDS OF WIND CAVE NATIONAL PARK
}

\author{
D. A. Shown \\ N. F. Sloan \\ Department of Forestry \\ Michigan Technological University
}

\section{Objectives}

Wind Cave National Park began a prescribed burning program in 1972. Since that time various studies have been carried out to investigate what effect fire has on the vegetative communities within the Park. However, no study has dealt with the effects of fire on the bird and mammal population with in the grassland association.

The objectives of this investigation are to:

1. Census burned and unburned areas for populations of birds and mammals at various seasons of the year. The first year concentrated on evaluating resident populations. In the other year of the study, attempts will be made to examine spring, fall and winter densities.

2. The vegetation on the plots will be analyzed to demonstrate the importance of certain densities and stand composition for various species of birds.

\section{Methods}

Breeding Bird Census. Estimates of the species composition and breeding density of birds were made using the transect method developed by Emlen $(1971,1977)$. This procedure involves the determination of a detectability value for each species and the application of this value to the species count in a series of traverses through the census tract.

Prior to the census period, transect lines were established on the study area. Stakes, with plastic flagging attached, were placed 660 feet apart along a 2,640 foot line.

The census was conducted for three 5-day periods the first weeks in June, July, and August. The census was used to determine peak population levels following the technique of Davis (1965). Both the transect and control areas were traversed each day wi th random starting points selected to eliminate possible bias. The censusing was initiated at sunrise (Jarvinen et al. 1977). 
By design, censusing was confined to a six chain wide strip bisected by the transect line. A walking speed of $1.2 \mathrm{~km} / \mathrm{hr}$ combined with a 3 chain recording radius allowed for a six minute detection period for each bird.

Smalz Mammal Census. Censusing of small mammal populations was conducted using two different methods: the snap trap removal method and the capture-recapture method.

Paired victor snap traps were placed on a $10 \mathrm{~m} \times 7 \mathrm{~m}$ grid with the pattern centered on the transect line. There was a one chain interval between each of the 10 rows and $15 \mathrm{~m}$ between each of the seven stations on the same row. Traps were checked daily and all catches were aged, sexed, and weighed. Trapping took place between July 15 and August 6 , 1980.

A capture-recapture technique was also used on each of the study transects. This technique used Sherman rat-sized live traps placed on a $5 \times 7$ grid with approximately 1.4 chains between each of the seven rows and one chain between each of the five stations in a row. This grid was centered on the transect line. The traps were prebaited with a peanut butter-bacon grease mixture for two nights prior to setting. Traps were then set for four nights and closed during the day due to a number of animals succumbing to the heat. Captured animals were toe-clipped, sexed, aged, and weighed before being released.

Vegetative Analysis. The technique used for analysis of vegetation was the canopy-coverage method described by Daubenmire (1968). It encompasses estimating the percentage of cover within a Daubenmire frame occupied by a given species (a bare ground estimate was also made). To facilitate the percentage use of a computer to analyze the data, it was then coded in the following manner: $1=0-5 \%$ coverage; $2=5-25 \% ; 3=25-50 \% ; 4=50-75 \% ; 5=75-95 \% ; 6=95-100 \%$. A total of 126 plots per transect were coded using the above technique. The sampling was done during both periods when cool season and warm season plants were mature.

Results

All field work this year was concentrated on either pre-burn sites or post-burn areas of various ages. Table I presents the estimated population of the grasshopper sparrow (Ammodramus savannarum) and western meadowlark (Sturnella neglecta) on the various study areas. Table 2 indicates the number of small mammals captured using the snap trap method. Analysis on other data collected is in progress.

\section{Literature Cited}

Daubenmire, R. 1968. Plant communities. Harper and Row Publ., New York. $300 \mathrm{pp}$. 


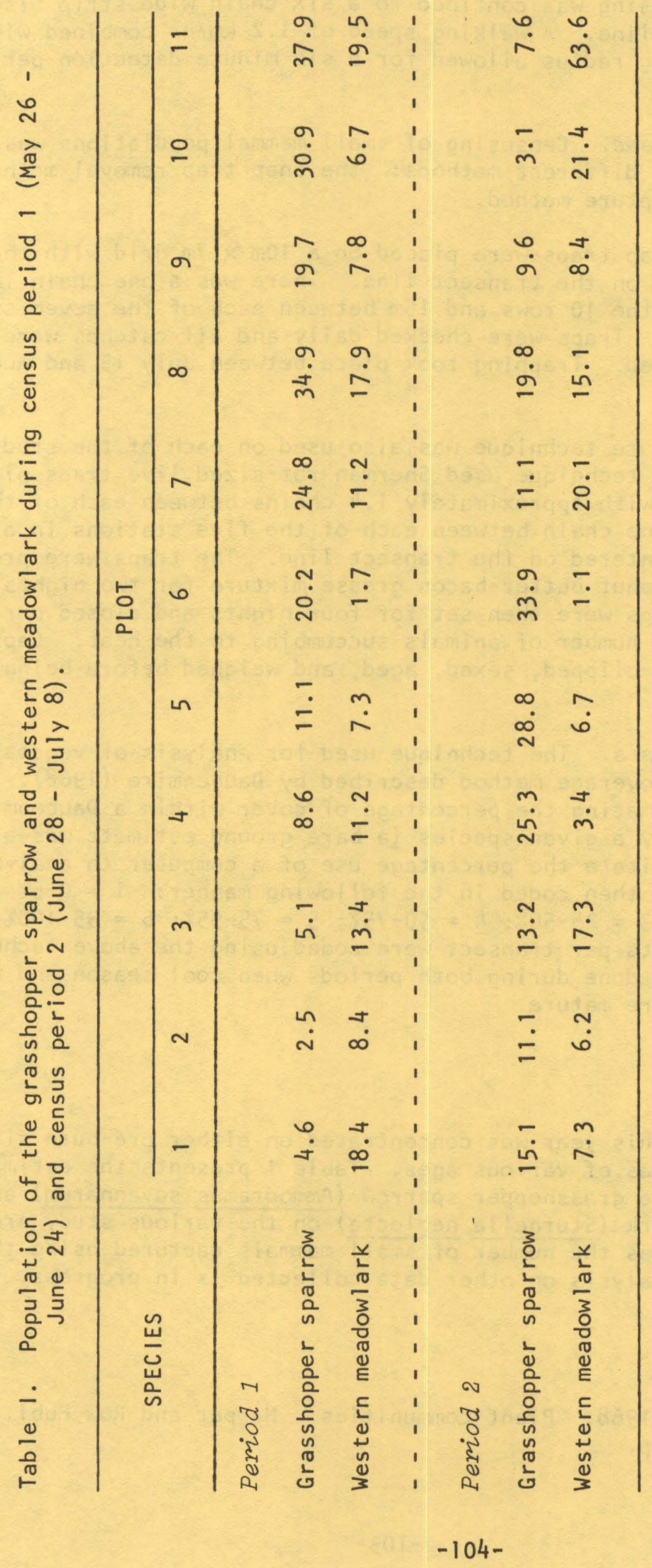


Table 2. Number of small mammals caught per 100 trap days.

\begin{tabular}{lc}
\hline Plot & Number of mammals per 100 trap days \\
\hline 1 & .73 \\
2 & .98 \\
3 & 2.21 \\
4 & 1.97 \\
5 & 2.30 \\
6 & 1.10 \\
7 & 1.04 \\
8 & 0.00 \\
9 & .29 \\
10 & .14 \\
11 & .44 \\
\hline
\end{tabular}


Davis, J. 1965. The singing male method of censusing birds: a warning. Condor 67:86-87.

Emlen, J. T. 1971. Population densities of birds derived from transect counts. Auk $88: 323-342$.

- 1977. Estimating breeding season bird densities from transect counts. Auk $94: 455-468$.

Jarvinen, 0., R. A. Vaisanen, and Y. Haila. 1977. Bird census results in different years, stages of the breeding season, and times of day. Ornis Fonnica 54:109-118.

\section{Acknowledgements}

I would like to thank the Wind Cave National Park staff for their cooperation and help in the first year of this project. A special thanks goes out to Rick Klukas for his help in orientation and plant identification, and to Dean Schilts for his information on past fires within the Park. 